\title{
Desenvolvimento de protótipo de cadeira de banho para indivíduos com paralisia cerebral tetraparética espástica
}

\author{
Fabíola Canal Merlin Dutra, ${ }^{\mathrm{a}, *}$ Reidson Pereira Gouvinhas ${ }^{\mathrm{b}}$ \\ a,*fabiola_canal@hotmail.com, UFRN, Brasil \\ bprofessor@ct.ufrn.br, UFRN, Brasil
}

\begin{abstract}
Resumo
Este estudo teve como proposta desenvolver um equipamento que atendesse as exigências motoras de indivíduos com paralisia cerebral tetraparética espástica, além de promover biomecânica postural adequada aos cuidadores para a atividade da vida diária referente ao banho. Inicialmente, o levantamento bibliográfico definiu os termos referentes à paralisia cerebral, atividade da vida diária especificando o banho e tecnologia assistiva, além de listar cadeiras de banho fabricadas pelas principais indústrias de produtos de tecnologia assistiva do mercado nacional. Posteriormente, a coleta dos dados obtida através da aplicação de formulário aos cuidadores em locais de tratamento médico-terapêutico captou dados específicos das condições atuais do banho e medidas antropométricas de ambos como parâmetros para elaboração do protótipo. A avaliação dos resultados obtidos, somada a experiência prático-clínica da pesquisadora e da equipe de engenheiros envolvidas no projeto, possibilitou o desenvolvimento e confecção do protótipo real da cadeira de banho.
\end{abstract}

Palavras-chave

Paralisia cerebral. Tecnologia assistiva. Atividade da vida diária. Cadeira de banho. Desenvolvimento de produto.

\section{Introdução}

A Paralisia Cerebral (PC) pode ser definida como um grupo não progressivo mas comumente mutável de distúrbios motores, principalmente no que diz respeito ao tônus e postura, secundários à lesão do sistema nervoso central desde a fase embrionária até os primeiros anos de vida. $\mathrm{Na}$ forma de manifestação clínica denominada PC tetraparética espástica, que caracteriza os indivíduos que compõem a amostra desta pesquisa, há um acometimento simétrico dos membros superiores e inferiores, além da musculatura do tronco e cabeça. São casos mais graves onde as aquisições motoras ocorrem tardiamente ou nem ocorrem (GlANNI, 2005). Sendo assim, o prognóstico para estes indivíduos é reservado, o que os faz dependentes de equipamentos para permanecerem em qualquer posicionamento antigravitacionário, como as posturas sentado ou em pé, ou mesmo para a locomoção.
Neste estudo, o foco foi dado para o banho, uma tarefa incluída nas Atividades da Vida Diária (AVD) cuja definição engloba todas as atividades direcionadas ao cuidado do indivíduo para com o próprio corpo (AMERICAN...,2002).Odirecionamento deste estudo à resolução da problemática relacionada ao banho de indivíduos com PC tetraparética espástica deveu-se, principalmente, aos relatos e mesmo queixas frequentes dos cuidadores sobre a falta de equipamento adequado para a realização desta tarefa, informação obtida na prática clínica da pesquisadora, já que ainda são escassos os trabalhos sobre esse tema.

Atualmente, a tendência do mercado é a ampliação de produtos destinados a atender grandes parcelas da população, objetivando proporcionar um design que atenda as exigências ou necessidades de pessoas com ou sem incapacidades (deficiências), entretanto o processo de desenvolvimento de 
um produto destinado a um grupo de usuários com características específicas (pessoas com incapacidades) merece destaque. Neste contexto, apesar deste processo seguir os mesmos passos do desenvolvimento de qualquer outro produto, faz-se necessário ampliar a compreensão acerca das características, necessidades, preferências e estilo de vida desses usuários, caracterizados neste estudo por indivíduos com paralisia cerebral tetraparética espástica, e de seus cuidadores, os consumidores. Entende-se por consumidor um indivíduo ou grupo de indivíduos que, frente a uma necessidade, efetua a compra de um produto ou serviço. Consumidor e usuário são considerados sinônimos quando ambos cumprem o mesmo papel, ou seja, quando o indivíduo compra o produto para seu próprio consumo ou uso (SOARES; MARTINS, 2000). No que se refere ao âmbito deste estudo, as palavras "consumidor" e "usuário" serão usadas de forma distinta. Assim, "consumidor" é aquele indivíduo que compra o produto (ou seja, a cadeira de banho) e que, neste estudo, é representado pelo cuidador. Já "usuário" é o indivíduo que efetivamente usa o produto, ou seja, o indivíduo com PC tetraparética espástica (pessoa com deficiência).

Pelo fato de a paralisia cerebral acometer fisicamente os indivíduos de formas diversas, cada um apresenta necessidades individuais específicas em termos do atendimento de seus problemas físicos. Além disto, no decorrer da vida, esses indivíduos crescem e sua estrutura corporal se modifica. Dessa forma, a rigor seria necessário fabricar cadeiras de banho específicas para cada indivíduo, o que, devido ao alto custo de produção, inviabilizaria comercialmente o produto. Assim, a solução técnica mais adequada é a fabricação de cadeiras de banho ajustáveis que atendam as diversas necessidades da maior parte desses indivíduos, acompanhando-os por períodos longos de sua vida.

Atualmente, os produtos disponibilizados no mercado nacional por empresas especializadas na fabricação/comercialização de equipamentos de tecnologia assistiva direcionados a esse público apresentam pouca variedade em relação a uso de acessórios, design e dimensões. Tais fatores podem limitar 0 atendimento das exigências motoras desses usuários de maneira satisfatória. Já dentre os produtos disponibilizados no mercado internacional, obtidos através de pesquisa realizada em sites e catálogos, alguns sistemas de cadeira de banho, de acordo com as descrições, parecem atender mais adequadamente as necessidades desses usuários. Entretanto, devido ao alto custo de compra e importação, sua comercialização no mercado interno é restrita.
Diante disso elegeu-se a temática abordada neste trabalho: o estudo da função do produto e a determinação dos fatores que adicionam valor a ele, analisando as necessidades do usuário (indivíduo com PC tetraparética espástica) e do consumidor (cuidador).

Nesse contexto, essa pesquisa - desenvolvida no âmbito do Programa de Pós-Graduação em Engenharia de Produção da Universidade Federal do Rio Grande do Norte, no centro de pesquisa do Laboratório de Acessibilidade Integrada - LAl - orientou-se para o desenvolvimento de um protótipo de cadeira de banho para indivíduos com paralisia cerebral tetraparética espástica atentando para as características físicas ideais de usabilidade do produto, buscando igualmente despertar o possível interesse de indústrias da área médica hospitalar para a sua fabricação.

\subsection{Paralisia cerebral $\mathrm{x}$ atividade de vida diária $\mathrm{x}$ banho}

A Organização Mundial de Saúde (OMS) define o termo paralisia cerebral como encefalopatia crônica não progressiva da infância consequente de uma lesão estática ocorrida antes, durante ou após o nascimento do indivíduo e que afeta o Sistema Nervoso Central(SNC)em fase de maturação estrutural e funcional. É uma disfunção predominantemente sensório-motora, envolvendo distúrbios no tônus muscular, postura e movimentação involuntária (MANCINl et al., 2002).

Segundo Mancini et al. (2002), em países subdesenvolvidos ou em desenvolvimento a incidência da PC é maior que nos países desenvolvidos, com índices de até 7:1.000. No Brasil estimam-se cerca de 30 a 40 mil novos casos por ano. A mesma autora descreve que nos últimos anos tem-se observado um aumento nos índices de incidência da PC que pode estar relacionado à melhoria dos cuidados médicos durante o parto, com o aumento da sobrevivência de indivíduos em condições de nascimento cada vez mais extremas baixa idade gestacional e baixo peso -, considerados fatores de predisposição para a instalação do quadro de paralisia cerebral.

A PC é classificada clinicamente de acordo com o tipo de comprometimento motor e distribuição do mesmo, o que determina o quadro clínico de manifestação. A desordem motora está diretamente relacionada com a área do SNC lesada (GIANNI, 2005). Na PC tetraparética espástica enquadram-se indivíduos que apresentam comprometimento motor global, ou seja, todas as partes do corpo 
são afetadas, condição resultante de uma lesão mais acentuada. Nos casos mais graves, apesar de as sequelas motoras variarem, frequentemente os indivíduos apresentam controle de cabeça e tronco insuficiente ou mesmo ausente, devido ao tônus dos músculos cervicais e do tronco estar habitualmente diminuído (GIANNI, 2005). Esses indivíduos dependem de suporte proporcionado por equipamentos para se manterem posicionados durante a execução das atividades da vida diária, como durante a atividade do banho focada neste estudo, ou mesmo para se locomoverem, neste caso com cadeira de rodas (GAUZZI; FONSECA, 2004).

0 termo Atividades da Vida Diária (AVD) é definido pela American Occupational Therapy Association (AMERICAN..., 2002, p. 609) como:

[...] atividades orientadas para o cuidado do indivíduo para com o próprio corpo - também chamadas de Atividades Básicas da Vida Diária (ABVD) ou Atividades Pessoais da Vida Diária (APVD)". Constituem "tarefas" das AVD o banho, o controle dos esfíncteres, o vestir-se, o comer ou alimentar-se, a mobilidade funcional, o cuidado com os equipamentos pessoais, a higiene pessoal e o autocuidado, a atividade sexual, o dormir/ descansar e o uso do vaso sanitário.

A OMS através da Classificação Internacional de Funcionalidade (CIF) apontou recentemente que a condição de saúde do indivíduo está diretamente relacionada à sua funcionalidade, que engloba todas as funções do corpo, atividades e participação. Qualquer condição que afete sua saúde, de maneira temporária ou permanente, gera um estado de incapacidade, que inclui deficiências, limitação de atividades ou restrição na participação (ORGANIZAÇÃO..., 2003).

Sabe-se que quanto mais comprometido motoramente for o indivíduo, maiores serão as dificuldades na realização das AVD, o que restringe sua participação tornando-o dependente em relação aos cuidadores, quadro compatível ao dos indivíduos que participaram deste estudo.

Para indivíduos mais severamente comprometidos, a limitação na participação torna-se inevitável, sendo necessária a identificação por parte da equipe avaliadora das necessidades dos cuidadores na realização das atividades, de forma a proporcionar uma intervenção que potencialize o desempenho ou facilite a ação dos cuidadores durante a sua execução. Shepherd (2001) descreve que indivíduos com limitações físicas variadas normalmente apresentam dificuldade na realização das AVD, sendo a autonomia no banho inexistente para crianças com limitação de: força, Amplitude de Movimento (ADM), estabilidade postural e manipulação ou destreza das mãos. Se o indivíduo mantém-se instável na postura sentada, certamente terá dificuldade de relaxar e se manter na posição. Além disso, este quadro comumente associa-se a deformidades osteoarticulares causadas por contraturas nas articulações dos joelhos e quadril, que contribuem ainda mais para um sentar instável (SHEPHERD, 2001).

A ausência do controle postural, caracterizada pelo déficit ou ausência do controle cervical (cabeça e pescoço) e do tronco, faz com que esses indivíduos necessitem de auxílio externo para permanecerem sentados, incluindo-se a possibilidade da utilização de acessórios como cintos, apoio de cabeça e apoios laterais para promoção de estabilidade, segurança e conforto. Tais acessórios também devem proporcionar postura adequada para o cuidador durante a atividade do banho.

Os resultados do estudo de Tabaquim e Lamônica (2004) evidenciam que as dificuldades percebidas pelos cuidadores durante a atividade do banho foram principalmente com a movimentação desses indivíduos com comprometimento motor severo.

A resolução requer uma intervenção com estratégias compensatórias, com uso de tecnologia assistiva desde a intervenção no ambiente em que se executa a tarefa do banho até a utilização de dispositivo que mantenha o indivíduo na postura sentada (cadeira de banho). Para Shephered (2001), as estratégias compensatórias podem incluir a remodelação ou reestruturação do ambiente, selecionando dispositivos de assistência ou desenhando métodos alternativos que favoreçam a autonomia. Essas estratégias também incluem assistência ao cuidador principalmente no que se refere a adultos e às crianças maiores e mais pesadas.

\subsection{Tecnologia assistiva}

A Tecnologia Assistiva (TA), ciência que agrega saberes diversos e profissionais da saúde (fisioterapeutas, entre outros), da área tecnológica (engenheiros, entre outros) e demais áreas, é definida por Cook e Hussey (2002) como sendo a ciência que trata da aplicação de qualquer item, peça, equipamento, serviço ou sistema de produto, seja ele de alta ou baixa tecnologia, adquirido comercialmente, modificado ou feito sob medida, utilizado para aumentar, manter ou devolver a capacidade funcional dos indivíduos com deficiência. 
Neste contexto, a implantação do uso de equipamentos destina-se a assistir, aumentar ou favorecer o desempenho funcional (performance) do indivíduo frente a uma tarefa a ser realizada, que neste estudo refere-se exclusivamente a atividade da vida diária banho. Assim, nesse estudo a TA objetiva intervir oferecendo equipamento adaptativo que promova o posicionamento sentado adequado do indivíduo com paralisia cerebral tetraparética espástica, além de proporcionar biomecânica postural favorável ao cuidador durante a execução da tarefa. A escolha de um dispositivo de assistência, ou seja, um equipamento que promova o aumento e/ou participação do indivíduo com incapacidade na execução de uma atividade, pode ser uma tarefa complexa. Todas as limitações e necessidades do usuário, do cuidador e do ambiente devem ser consideradas, pois seu somatório definirá como o dispositivo funcionará e como sua função será percebida (PAIN; McLELLAN, 2003).

Segundo Bain e Cook (1997 apud ANGELO; BUNING, 2005, p. 395) "as avaliações são guiadas pelas necessidades do consumidor". Porém, os objetivos e necessidades também podem ser identificados pela família, ou cuidadores, caso o usuário apresente dificuldades para comunicar suas necessidades ou desejos (ANGELO; BUNING, 2005).

0 sucesso no uso e aceitação de um dispositivo de TA por parte do usuário e de seus cuidadores, seja ele produzido de forma seriada (em massa) ou confeccionado sob medida, frequentemente envolve um somatório de fatores econômicos, ergonômicos e estéticos na sua fase de desenvolvimento, os quais, juntos, agregam valor ao produto que, enfim, se destina a ampliar ou facilitar a participação do indivíduo e/ou cuidadores nas atividades, refletindo-se numa melhor qualidade de vida.

0 conhecimento ou a capacidade de prever as percepções de usuários e consumidores sobre as funções de um produto, de antever a importância que eles atribuem a essas funções, são caminhos que ampliam o conhecimento sobre o produto (BAXTER, 2003). Esse conhecimento, construído sob a óptica da díade usuário/consumidor e sob o ponto de vista funcional do produto possibilita o desenvolvimento de novos conceitos. Quando este raciocínio é empregado durante a elaboração ou avaliação de um dispositivo de tecnologia assistiva é possível prever detalhes sobre os aspectos conceituais e as especificações técnicas do equipamento.

\subsection{Desenvolvimento de produto}

Segundo Soares e Martins (2000), é de suma importância que os produtos sejam desenvolvidos de acordo com as características de seus consumidores/ usuários. Assim, estabelecer a interrelação entre as características do produto e as necessidades do usuário pode ser considerada a fase mais importante no desenvolvimento de um produto.

Pode-se afirmar que todo o processo de desenvolvimento de um novo produto passa inicialmente pela identificação da oportunidade, seguida pelo planejamento do produto para que essa oportunidade detectada possa ser explorada e por fim pelo teste do protótipo. 0 design de um novo produto é considerado completo quando, na sua fase de planejamento, se tem a previsão de quem irá adquiri-lo e de como será vendido (benefícios ofertados), a fim de que o conjunto de características apresentadas ao consumidor no novo produto esteja além das encontradas nos produtos que já existem no mercado (URBAN; HAUSER, 1993).

Dentre as várias propostas para o processo de design expressas na literatura, a Figura 1 mostra o processo de design seguido neste estudo, apresentado por Urban e Hauser (1993), por se tratar de uma representação clara e sucinta de todo o processo, onde, em um aspecto geral, visualizam-se à esquerda todas as responsabilidades de execução do projeto e à direita as várias análises sobre o cliente.

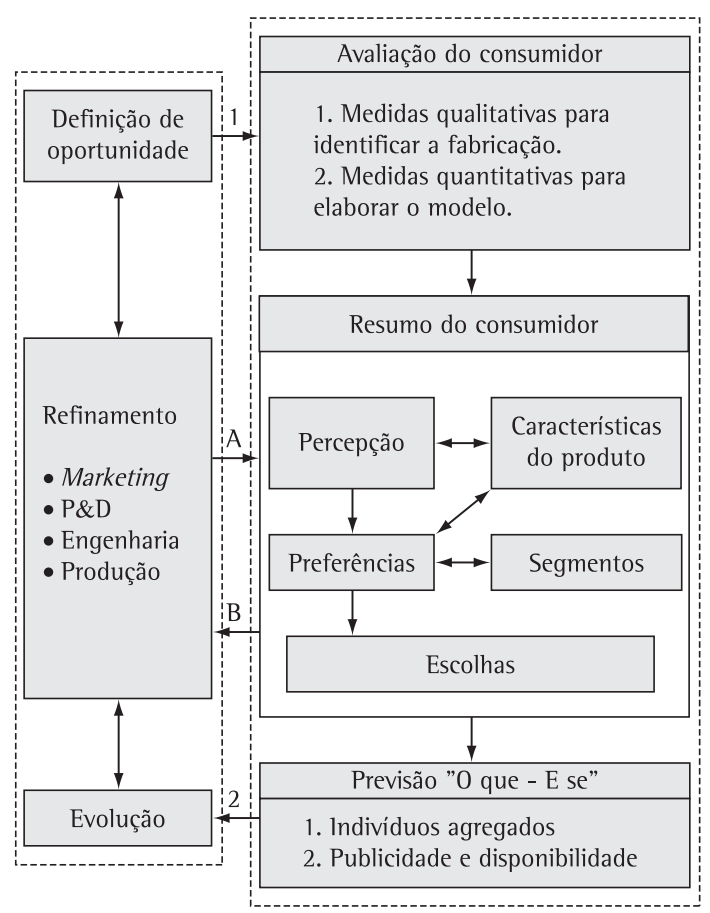

Figura 1. Processo de design de um novo produto. Fonte: Urban e Hauser (1993, p. 167). 
A análise da figura permite a visualização do processo de design seguido para o desenvolvimento do produto proposto, neste estudo a cadeira de banho para indivíduos com paralisia cerebral tetraparética espástica. 0 primeiro passo é caracterizado pela definição da oportunidade, identificada neste caso pela pesquisadora com prática clínica no trato com as condições físicas e posturais do cuidador e do indivíduo com PC durante a atividade do banho.

A análise relacionada ao cliente, neste estudo constituído pela díade consumidor e usuário, sugere que a sucessão nas etapas de design que leva ao desenvolvimento de um novo produto com sucesso imbrica-se na captação das necessidades do usuário. Compreendida por Urban e Hauser, 1993, como resultado de avaliação qualitativa e quantitativa do cliente, apreendidas neste estudo através de formulário que avaliou a situação do banho dos indivíduos com PC tetraparética espástica que participaram deste estudo e captou quais atributos são mais importantes para o consumidor do produto a ser elaborado, fornecendo informações iniciais que depuraram conceitos do novo produto.

Segundo Urban e Hauser (1993), para que se tenha a estratégia de desenvolvimento de um novo produto, os dados obtidos dos consumidores devem estar organizados e estruturados como o modelo sugerido na Figura 1, onde a estrutura organizada está baseada nas características do produto, na percepção, preferências dos consumidores, segmentação e escolha, para auxiliar no diagnóstico do mercado. Juntos, estes identificam o conjunto de benefícios que são a chave para o sucesso do novo produto, informações estratégicas para alcançar os benefícios captados no design do novo produto.

Baxter (2003, p. 8) reforça que:

[...] o fator mais importante, e provavelmente o mais óbvio, é o produto ter diferenciação em relação a seus concorrentes no mercado e apresentar aquelas características valorizadas pelos consumidores.

Ainda segundo Urban e Hauser (1993), antes de se iniciar a produção do novo produto, sua confecção requer respostas do consumidor como "o que" e "se" pode fazer? As características "o que/se" constituem a base da evolução de uma oportunidade de negócio. Na evolução do gerenciamento de um novo produto pesquisado, fatores como custos da produção, políticas governamentais, considerações tecnológicas, avaliação de material, da mão-de-obra, da complementabilidade com a linha de produção e outros aspectos de um novo produto introduzido levam à decisão de fazê-lo ou não. Nesta pesquisa, essa fase não foi considerada, uma vez que não fez parte dos objetivos dela, devendo o assunto ser retomado em considerações futuras.
Em relação ao processo de refinamento do mercado para o qual o produto deste estudo se destina, considera-se já bastante condensado, não ocorrendo grandes variações na preferência, já que as características físicas exigidas no produto estão voltadas a atender exigências semelhantes de um público específico. Esta fase depende da integração efetiva do marketing, P\&D (pesquisa e desenvolvimento), engenharia, produção e outras áreas funcionais das organizações.

Por fim, a Figura 1 mostra que o processo de design é interativo e que não ocorre em uma única etapa, sendo que todas as fases do processo ocorrem sequencialmente.

\subsection{Cadeiras de banho}

0 conjunto de dispositivos de assistência ao banho é comumente disponibilizado em lojas especializadas de produtos médico-hospitalares, catálogos de produtos de tecnologia assistiva e sites da internet, podendo variar nas suas características. As cadeiras de banho mais comumente encontradas no mercado nacional são disponibilizadas por empresas citadas como referência na fabricação e comercialização de produtos de tecnologia assistiva.

De maneira geral, a maioria das fabricantes desses produtos confeccionam cadeiras de banho com características semelhantes como: estrutura em alumínio ou aço, assento sanitário acoplado a estrutura metálica de sustentação, rodas que se diferenciam na dimensão do aro e freios e a não variação das dimensões, o que pode restringir sua indicação ao público adulto.

Outra linha de cadeiras de banho, restrita a poucas indústrias, possui características que merecem destaque: variação nas dimensões do produto, o que amplia sua indicação para idades variadas; assento/encosto em formato de concha ou reto, que favorece a acomodação do usuário; sistema de regulagem de altura que favorece a biomecânica postural do cuidador; material antiderrapante no assento; e acessórios como cintos de segurança e apoio de cabeça. Cabe ressaltar que a maioria desses equipamentos apresenta uma ou algumas dessas características.

\section{Metodologia}

A obtenção dos dados técnicos sobre os modelos de cadeira de banho para pessoas com deficiência física disponíveis no mercado nacional requereu inicialmente a realização de uma investigação por 
meio de visitas a sites, contatos via e-mail e por telefone às principais empresas de equipamentos de tecnologia assistiva do país, situadas nos estados do Rio Grande do Sul, São Paulo, Goiás, Rio de Janeiro e Minas Gerais.

Inicialmente buscou-se aprofundar os conhecimentos sobre as características da população em estudo, indivíduos com paralisia cerebral tetraparética espástica e seus cuidadores, bem como relacionar as necessidades desses indivíduos à atividade da vida diária banho através do levantamento bibliográfico. Foram estabelecidas as características clínicas dos usuários que participaram do estudo bem como detectadas as dificuldades e/ ou facilidades encontradas pelos cuidadores durante a realização do banho em relatos prévios, além de avaliada a importância do uso de equipamento de tecnologia assistiva durante esta tarefa. Também foram refundamentados os conceitos gerais já existentes sobre o tema.

A amostra estudada, definida como a díade usuário-consumidor, caracterizou-se como não probabilística e intencional. Assim, foram estudados 58 indivíduos com diagnóstico de paralisia cerebral tetraparética espástica, de ambos os sexos e com idade mínima de três anos, e respectivos cuidadores, também de ambos os sexos, sem faixa etária estipulada e não necessariamente da família do usuário. Todos os indivíduos frequentavam centros de reabilitação e/ou clínicas destinadas ao atendimento médico-terapêutico da população da pesquisa situados na cidade de Natal/RN.

A idade mínima de três anos para o usuário participar da pesquisa foi estabelecida devido às queixas e dificuldades relatadas pelos cuidadores na realização do banho de indivíduos dessa faixa etária - dados obtidos na prática clínica diária da pesquisadora. Tais queixas se acentuam a partir do terceiro ano de idade do usuário, quando os equipamentos usualmente disponíveis no mercado, como, por exemplo, as banheiras plásticas facilmente encontradas no comércio, normalmente utilizadas por bebês que não necessitam de cuidado especial, deixam de atendê-lo satisfatoriamente por sua estatura.

Em um segundo momento, dados sobre a atual condição de realização da atividade banho, além das necessidades vivenciadas rotineiramente sob o ponto de vista dos cuidadores, foram obtidos junto a eles através da aplicação do formulário semiestruturado. Foram também realizadas e registradas as medidas antropométricas específicas dos indivíduos com paralisia cerebral e de seus cuidadores. Tais dados foram utilizados para nortear a projeção do protótipo.
Foi realizada contagem manual dos achados e separação dos itens de interesse para constituição do equipamento. Para o tratamento dos dados, deu-se precedência ao caráter representativo sistemático dos resultados: fundamentalmente, estabeleceu-se relação entre os resultados obtidos pelo formulário com resultados previamente examinados no levantamento bibliográfico, ou seja, aqueles derivados de teorias e estudos realizados anteriormente.

Em seguida, buscou-se delinear as características ideais de um produto que ao mesmo tempo atendesse as necessidades de posicionamento e conforto durante a atividade banho tanto dos indivíduos com paralisia cerebral tetraparética espástica - usuários - quanto dos cuidadores que executam a tarefa - consumidores. Terminada a apreciação do referencial teórico partiu-se para a concepção, planejamento e execução do modelo de protótipo do produto.

0 processo de ideação do protótipo foi norteado pela definição de oportunidade percebida pela aplicação do formulário além de pela experiência clínica prática da pesquisadora, seguida do procedimento de retomada dos apontamentos feitos a partir da avaliação do consumidor sobre a realidade apreciada rotineiramente na tarefa banho (URBAN; HAUSER, 1993). 0 planejamento procedeu-se frente aos dados coletados seguindo a sequência lógica da Figura 1, já apresentada anteriormente. A execução do protótipo foi feita em parceria com pesquisadores do Curso de Pós-Graduação em Engenharia Mecânica e do Curso de Pós-Graduação em Engenharia de Produção do Centro de Tecnologia da Universidade Federal do Rio Grande do Norte (UFRN).

\section{Resultados e discussão}

Participaram da pesquisa 58 indivíduos usuários com diagnóstico clínico de paralisia cerebral tetraparética espástica, sendo 31 do sexo feminino e 27 do sexo masculino. A faixa etária da maioria dos usuários ficou entre 3 a 6 anos de idade. Cabe ressaltar que embora a idade mínima para o indivíduo integrar a amostra tenha sido estipulada em 3 anos, não houve limite para a máxima. Dos consumidores/cuidadores investigados, 56 são do sexo feminino e 2 do sexo masculino. Desses, 56 têm parentesco com o usuário e apenas 2 são cuidadores contratados. Em relação ao grau de escolaridade, 54 desses indivíduos frequentaram a escola, porém 29 não têm o ensino fundamental completo e nenhum dos entrevistados apresenta ensino superior, sendo que profissionalmente a maioria se limita às funções do lar. 
A condição socioeconômica das famílias dos indivíduos usuários é variável, com renda entre 1 a 5 salários mínimos. Tais dados indicam que a maioria das famílias envolvidas neste estudo concentrava-se em classes socioeconômicas menos favorecidas.

Em relação à atividade do banho, o local da casa predominantemente utilizado para realizá-la foi o banheiro (29), seguido da cozinha (17) e quintal (11). Dentre os equipamentos utilizados para o banho, banheira de bebê (19) e bacia de metal (12) foram os mais citados, independente da idade e estatura do indivíduo. Cabe ressaltar que frequentemente esses dispositivos são colocados sobre um móvel com o intuito de elevar o sistema, buscando melhor conforto do cuidador. Dos 58 indivíduos com PC tetraparética espástica, apenas 4 possuem cadeira de banho específica para suas necessidades físicas. Obteve-se também que para a maioria dos entrevistados (43) a atividade banho é repetida três ou mais vezes durante o dia.

Em relação ao grau de importância ou não de características como: segurança, conforto, ajuste de altura, facilidade de ser transportada, facilidade de limpar, leveza, facilidade de armazenamento, possibilidade de ser desmontada e de ser fechada, houve uma predominância entre os cuidadores na avaliação de segurança (49) e conforto (46) como características mais relevantes quando da escolha de um equipamento para o banho. Cabe ressaltar que esta análise é apenas uma indicação daquilo que poderia ser considerado mais relevante para os cuidadores e não uma inferência direta a partir de dados apresentados, uma vez que não houve investigação do grau de importância das características analisadas de forma comparativa.

Em relação aos possíveis tipos de materiais utilizados na confecção da estrutura do equipamento, o alumínio (33) e o plástico (16) foram os mais citados, por serem materiais leves e resistentes às condições do banho. Dentre os selecionados para o sistema de assento/encosto da cadeira de banho, o tecido impermeável foi o mais citado (42). Também foram citados revestimentos do assento/encosto em tecido de lona (3), fio (3), fibra (1) e tiras de plástico (6).

Em relação ao posicionamento do assento/encosto, dentre as três opções oferecidas ao respondente mostradas nas Figuras 2a, b e c, a preferencialmente escolhida (44 respostas) foi aquela na qual o indivíduo mantém-se sentado numa posição intermediária entre o sentar e o deitar (Figura 2b), mantendo-se fixo o ângulo entre assento e encosto e favorecendo-se a manutenção da postura sentada contra a gravidade.

Quanto à presença de acessórios no equipamento, foram mais citados apoio de cabeça e cinto de segurança, seguidos de apoio para os pés e portatoalhas. Já a cor do equipamento foi considerada irrelevante para a maioria dos entrevistados.

Medidas antropométricas de tamanho, largura e profundidade do assento e altura total do encosto serviram de base para estabelecer as dimensões ideais do novo equipamento que atendesse o indivíduo com PC tetraparética espástica, visto que não foram encontrados na literatura pesquisada dados específicos dessa população. Como a proposta também objetiva promover adequado alinhamento biomecânico ao cuidador durante a execução da tarefa na postura em pé, as medidas estatura e altura do cotovelo ao chão com o indivíduo em pé também serviram de parâmetro na idealização do produto cadeira de banho. Apesar da literatura fornecer parâmetros antropométricos que atendem essa necessidade quando se trata da população em geral, optamos por aferir essas medidas e compará-las com os dados já existentes, uma vez que nosso público é a população de uma região determinada do país.

Em relação ao peso corpóreo, a maioria dos usuários pesa entre 10 e $20 \mathrm{~kg}$, o que condiz com o registrado para a faixa etária destes participantes, que em sua maioria estavam entre 3 a 6 anos de idade. Já para a estatura, a maioria apresentou valores inferiores a $100 \mathrm{~cm}$. Para medição deste dado, as limitações físicas impostas pelo estado físico dos indivíduos - presença ou não de contraturas e/ou deformidades esqueletais - foram respeitadas. (a)

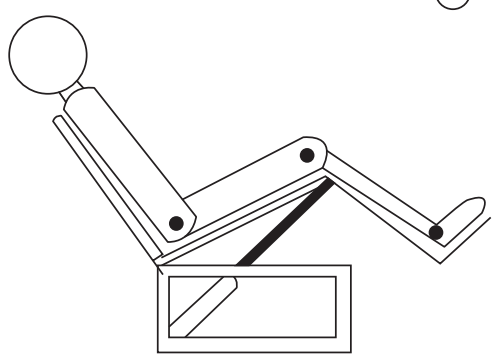

(b)

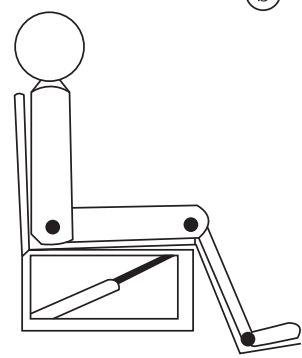

(c)

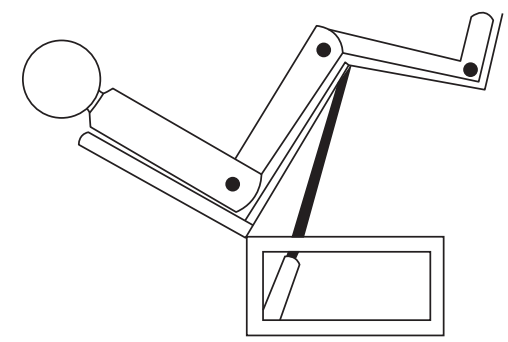

Figura 2. Posicionamento do assento/encosto para o protótipo. 
Para 35 indivíduos usuários, a maioria, a medida profundidade do assento apresentou valores entre 21 e $30 \mathrm{~cm}$. A medida largura do assento, na maioria dos casos (35), ficou entre 21 e $25 \mathrm{~cm}$, porém deve-se considerar que para as cadeiras de nove indivíduos as medidas foram inferiores a esses valores e que 14 outras apresentaram dimensões superiores a eles. Ainda cabe ressaltar que, dentre estas, duas apresentaram medida entre $40 \mathrm{~cm}$ e $50 \mathrm{~cm}$, o que configura uma grande variação nas dimensões acomodativas do assento para indivíduos de diferentes idades/estaturas.

Outra medida antropométrica essencial para se projetar equipamento cuja função é posicionar indivíduo sem controle postural ou com controle deficitário na postura sentada é a altura do tronco e cabeça, que caracterizam o comprimento do assento no dispositivo a ser projetado. As medidas referentes a este quesito variaram entre 40 e $80 \mathrm{~cm}$, a medida mínima e máxima obtidas, respectivamente.

Com base no levantamento bibliográfico previamente realizado e na experiência clínica da autora, a mesma considerou que as medidas antropométricas do usuário largura e altura do tronco/cabeça serviriam de parâmetro para o dimensionamento de um projeto inicial, embora a inexatidão dessas medidas não interfira diretamente no posicionamento sentado do indivíduo, bastando o equipamento ter dimensão suficiente para sua acomodação. Situação oposta envolve a medida antropométrica profundidade, essencial para a manutenção ou obtenção da postura sentada. No geral, quando um indivíduo é posicionado num assento cuja profundidade é maior ou menor que a dele, ocorre uma desestabilização do quadril, impossibilitando-o de manter-se sentado adequadamente. A postura assim adquirida, além de não propiciar conforto, pode promover a exacerbação de reflexos primitivos (como, por exemplo, a extensão excessiva), impossibilitando que o indivíduo faça uso do equipamento.

Em relação à estatura dos cuidadores, a maioria dos entrevistados (41 participantes) apresentou altura entre 150 e $160 \mathrm{~cm}$. Cabe ressaltar que a estatura mínima e máxima encontradas foram 144 e $175 \mathrm{~cm}$, respectivamente, significando então variação de $31 \mathrm{~cm}$. A mesma variação ocorreu em relação à distância do cotovelo ao chão: os valores das distâncias mínima e máxima foram 85 e $115 \mathrm{~cm}$, respectivamente, resultando variação de $30 \mathrm{~cm}$.

\section{Desenvolvimento do protótipo}

Após identificação da oportunidade, da análise detalhada dos produtos disponíveis no mercado nacional e traçadas as características físicas que atendem as exigências de usuários e consumidores, bem como captadas as percepções e preferências dos respondentes, iniciou-se a elaboração do projeto e concepção do protótipo da cadeira de banho para indivíduos com comprometimento motor severo.

0 que norteou o projeto conceitual foram as necessidades dos consumidores (cuidadores) e usuários (indivíduos com PC tetraparética espástica) estudadas umas em relação a outras: a) possibilidade de regulagem do assento (aumento e redução da profundidade) e do apoio de cabeça acoplado sobre o encosto (aumento e redução de altura), com o intuito de atender uma maior gama de usuários, bem como para permitir que o produto seja utilizado à medida que o usuário cresça; b) regulagem da inclinação do sistema assento/encosto, com o objetivo de proporcionar maior apoio e consequente estabilidade e conforto ao usuário, bem como para facilitar a tarefa do banho para o cuidador; c) cinto de segurança ajustável no comprimento e regulável sobre a superfície de apoio (assento e/ou encosto) para garantir a segurança ao usuário, seja durante deslocamento da cadeira até o local do banho, seja durante o próprio banho, a fim de que ele não corra risco de queda ou escorregamento; d) facilidade de transporte, de tal forma que o produto possa ser levado para diversas partes da casa sem que o cuidador necessite fazer grande esforço para realizar o deslocamento e/ou possa ser utilizado durante viagens; e) garantia de que o equipamento possa transitar em diversos ambientes (sala, quarto, cozinha etc.) da residência ou local do uso; e f) facilidade de operação e condução do produto quando da sua utilização. Assim, realizar todas as regulagens do produto (profundidade do assento, inclinação do assento/encosto e altura do equipamento) devem ser tarefa fácil, que não demande grandes esforços por parte do cuidador. Como todos estes aspectos são igualmente importantes para que a atividade do banho seja realizada com sucesso, optou-se por considerar todas estas características listadas da mesma importância.

A preocupação de gerar um produto que atendesse todas as exigências físicas demandadas pelos usuários e que também atendesse aos anseios e desejos dos consumidores orientou o desenvolvimento do protótipo, confeccionado em aço na sua estrutura e revestido por tecido telado no assento e no encosto e cujas dimensões máximas e mínimas correspondem à variação dos dados antropométricas dos usuários e consumidores, obtidos durante a pesquisa. 0 desenvolvimento do protótipo concentrou-se primordialmente em aspectos relacionados à funcionalidade do produto, os aspectos estéticos foram considerados secundários. A análise crítica do protótipo foi dividida em análise da tarefa e ergonomia e análise das funções do produto.

Levando em conta as demandas de usuários e cuidadores, optou-se por adotar como parâmetros 
norteadores as características descritas por Kroemer et al. (1999 apud SOARES; MARTINS, 2000) como fundamentais para produtos projetados para pessoas com deficiência. Da análise crítica assim realizada sobre o produto final desenvolvido (protótipo), depreenderam-se as seguintes observações:

- Segurança física: apesar de ser um equipamento destinado a operar em situação de risco de escorregamento e queda, como pode ser considerado o banho, projetou-se uma estrutura estável, apropriada para acomodar satisfatoriamente os usuários, sejam eles crianças ou adultos, com acessórios de segurança como cintos (Figura 3a) e rodízios com travas (Figura 3b), todos de fácil manejo;

- Portabilidade: a capacidade de ser fechado el ou desmontado garante ao produto a fácil transportabilidade, seja pelo carregamento manual ou no portamalas de veículos; e a presença de rodízios móveis (Figura 3b) confere ao equipamento, além do fácil deslocamento, a possibilidade de manobras mesmo em espaço restrito;

- Usabilidade: a simplicidade do design do produto confere facilidade à sua utilização, com partes ajustáveis por sistemas de travas simples, como observado na Figura 4, as quais possibilitam a regulagem da altura do equipamento (Figura 4a); o acionamento da trava pode ser executado com apenas uma mão, possibilitando o deslizamento de partes da estrutura que resultam no seu aumento ou diminuição em uma regulagem condizente com a estatura do cuidador. 0 deslizamento da estrutura do encosto sobre um trilho (Figura 4b) confere ao equipamento a possibilidade de ajustar a profundidade do assento, girando-se o dispositivo da trava para realizar o travamento na medida desejada. E, por fim, uma haste dentada na região posterior do equipamento (Figura 4c) integra o sistema de inclinação do assento/ encosto, proporcionando ampliada variabilidade da postura sentada;

- Conforto físico e adequação pessoal: a possibilidade de ajuste na profundidade do assento, como mostrado na Figura 5; possibilidade de ajuste na variação da altura do apoio de cabeça; e possibilidade de ajuste na inclinação do sistema de assento/encosto proporcionam o conforto físico do usuário, ao mesmo tempo que a regulagem de altura do dispositivo, como um todo, promove biomecânica favorável ao cuidador/consumidor na execução da tarefa banho;
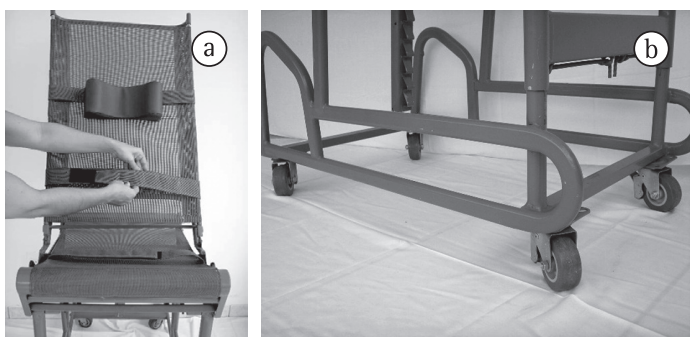

Figura 3. Características de segurança física e transportabilidade do protótipo: a) cintos de segurança para assento e encosto, com possibilidade de regulagem; e b) rodízios com travas.

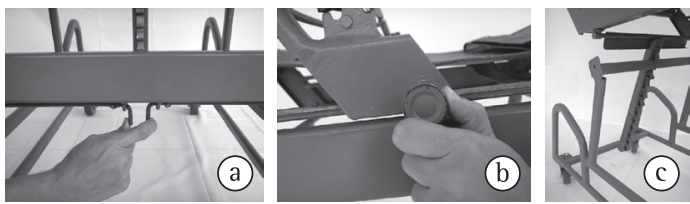

Figura 4. Característica do protótipo em relação à usabilidade: a) sistema de trava que possibilita a regulagem da altura do equipamento; b) sistema de deslizamento do encosto sobre o assento; e c) sistema de inclinação do assento/encosto.
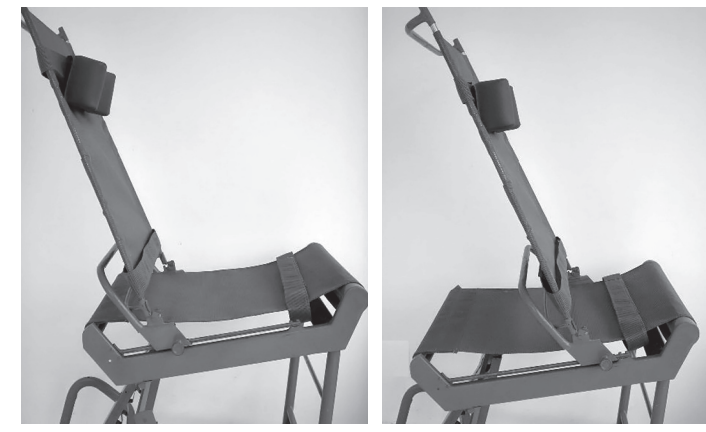

Figura 5. Característica do protótipo em relação ao conforto físico e adequação pessoal: variação da profundidade do assento.
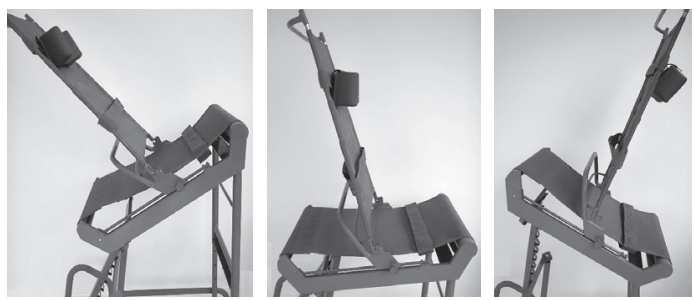

Figura 6. Característica do protótipo em relação a flexibilidade e compatibilidade: sequência da variação de inclinação.

- Flexibilidade e compatibilidade: possibilidade de regular a altura e ao mesmo tempo a inclinação para frente ou para trás do assento/encosto com o equipamento em uso, o que facilita a transferência do usuário para superfícies mais baixas ou mais altas, como da cadeira de banho para a cama ou cadeira de rodas e vice-versa (Figura 6);

- Facilidade de montagem e manutenção: apesar de a estrutura do protótipo não ter sido confeccionada em materiais considerados mais leves, o manuseio das peças projetadas para serem encaixadas e ajustadas é fácil, dispensando qualquer esforço excessivo para sua execução. Certamente, o uso daqueles materiais, que sejam adequados também para a situação proposta, confere ao produto a qualidade de poder ser ajustado enquanto o usuário está posicionado sobre o assento; $\mathrm{e}$

- Facilidade de reparo e higienização: em relação aos acessórios ou partes como o assento e o encosto, houve a preocupação de que fossem confeccionados em materiais de fácil aquisição e manuseio. Para a confecção do assento e do encosto foi utilizada tela constituída por tecido de poliéster de alta tenacidade recoberto com PVC que the confere um aspecto emborrachado, com 
ação antiderrapante. Os cintos de segurança e a faixa do apoio de cabeça foram confeccionados no mesmo material do assento/encosto, acrescido de velcro nas extremidades para execução do fechamento e garantia da possibilidade de ajuste. A opção de confeccionar acessórios em materiais de fácil aquisição e manuseio objetivou garantir a possibilidade de substituição do material quando necessário. Também houve a preocupação, no projeto do produto, de possibilitar a fácil retirada destes dispositivos, o que também contribui para uma melhor higienização, garantindo menos riscos à saúde do usuário.

Por se tratar de protótipo ainda em fase de teste, as características adequação, durabilidade e eficiência não puderam ser aferidas. 0 que se pode adiantar é que, apesar de não se ter realizado estudos direcionados para o mercado, no que se refere aos fatores de comercialização do produto, houve preocupação constante em projetar um produto de custo viável e de fácil manutenção (adequação). Ainda, que fosse durável o suficiente para acompanhar o indivíduo usuário em qualquer mudança de sua estrutura corporal (durabilidade/ adaptabilidade); e que atendesse, além das demandas físicas específicas do público usuário (indivíduos com PC tetraparética espástica), as necessidades do consumidor (cuidador), por meio da atenção ao favorecimento de uma melhor biomecânica postural durante a atividade, proporcionada, entre outros fatores, pela capacidade da regulagem de altura.

A somatória dessas características no produto pretende facilitar a execução da tarefa banho, com diminuição do tempo gasto em sua execução, diminuição do quadro álgico e consequente melhora da qualidade de vida de todos os envolvidos - esses são aspectos positivos relacionados à funcionalidade do equipamento.

Segundo Baxter (2003), as funções de um produto podem ser classificadas como principal, básicas e secundárias: a função principal explica a própria existência do produto, ou seja, no caso deste estudo, a função principal da cadeira de banho é posicionar o indivíduo usuário para o banho. Já as funções básicas são aquelas que fazem o equipamento funcionar, ou seja, para o produto idealizado nesta pesquisa pode-se caracterizar como funções básicas: manter o indivíduo usuário sentado com segurança e de modo a facilitar a atividade banho, sendo que para isso faz-se necessário um sistema de assento/encosto eficiente; e promover uma biomecânica favorável para o executor da tarefa, neste caso o cuidador, o que exige do dispositivo a possibilidade de regulagem da altura. E, por fim, são funções secundárias aquelas que suportam, auxiliam, melhoram o desempenho da função básica. Na cadeira de banho, a presença de acessórios como apoio de cabeça, cintos de segurança, porta-sabonete, porta-xampu, porta-toalha, entre outros, exemplificam estas funções.

\section{Conclusão e recomendações futuras}

O objetivo principal deste trabalho foi desenvolver um protótipo de cadeira de banho que atendesse melhor as exigências motoras de indivíduos com paralisia cerebral tetraparética espástica e que promovesse biomecânica postural adequada aos cuidadores desses indivíduos, visto que a maioria dos equipamentos pesquisados disponibilizados no mercado nacional, no geral, é desprovida de sistema acomodativo de assento e encosto, além de não oferecerem opções referentes ao tamanho, o que restringe seu uso a indivíduos adultos. Há cadeiras de banho específicas, restritas a poucas fábricas, que apresentam características favoráveis ao posicionamento sentado de indivíduos severamente comprometidos em relação ao quadro motor, porém essas não apresentam regulagem das suas dimensões no que diz respeito a assento e encosto, característica essa que promove, como resultado prático, o aproveitamento do equipamento por uma gama maior de indivíduos, de diferentes estaturas e diversas faixas etárias.

A análise da situação atual da realização da atividade banho de indivíduos com PC tetraparética espástica; das cadeiras de banho fabricadas nas principais indústrias de produtos de tecnologia assistiva do mercado nacional quanto aos diversos tipos de materiais utilizados na confecção da estrutura, assento/encosto e acessórios, dimensões, capacidade de ajuste, suporte de peso, design, durabilidade e praticidade (capacidade de dobrar/ desmontar); e a investigação das necessidades, preferências e expectativas dos possíveis consumidores do produto proposto forneceram subsídios para a confecção do protótipo.

A possibilidade de ajuste da altura do equipamento como um todo, de regulagem da inclinação do sistema assento/encosto (tilt), do ajuste de altura do apoio de cabeça e a possibilidade de alteração dos locais de colocação, ou mesmo a remoção dos cintos de segurança, somadas à possibilidade de variação da profundidade do assento de acordo com a estatura do usuário tornam o produto diferente dos demais pesquisados durante a execução deste estudo. Ênfase deve ser dada à possibilidade de regulagem/ajuste da profundidade do assento, fator inovador em relação aos produtos existentes no mercado nacional e considerado de fundamental importância para o bom posicionamento do indivíduo sentado.

Diante dos resultados encontrados nas análises e conclusões do trabalho, verificou-se que apesar dos objetivos propostos terem sido alcançados, com o desenvolvimento de um modelo de cadeira de banho que atende às necessidades expressas pelos que participaram da amostra deste estudo, o assunto ainda não esgotou seu conteúdo, mostrando a necessidade de mais estudos do dispositivo 
desenvolvido, já que o mesmo não foi testado em situação real de banho devido a restrição do tempo estipulado para o término da pesquisa.

Por considerar-se a elaboração de conceitos ligados à tecnologia assistiva assunto importante, oferecemos algumas sugestões ou direções para pesquisas que possibilitariam um melhor direcionamento daqueles que trabalham com pessoas com deficiência ou com o desenvolvimento de produtos destinados a atender as necessidades dessa parcela específica da população: realizar um estudo aprofundado acerca da viabilidade técnica e de custo de materiais aplicáveis à estrutura, assento/ encosto e acessórios que compõem o dispositivo, assegurando que o mesmo satisfaça o conjunto de demandas listadas como essenciais ao longo da pesquisa; realizar análise da execução da tarefa banho com o uso do protótipo, a fim de detectar as facilidades e/ou dificuldades enfrentadas pelos cuidadores no que tange a habilidade funcional e postura assumida durante o uso do dispositivo; realizar análise do posicionamento do usuário enquanto faz uso do equipamento, bem como se as alternativas de ajustes e acessórios do dispositivo se adequam ao usuário; investigar a viabilidade de custo e o estabelecimento de fabricação seriada do equipamento, bem como o real interesse comercial do mercado pelo dispositivo; e realizar uma análise mercadológica do produto, avaliando aspectos como viabilidade de mercado, marca, cor, modelos e suas variações, canais de comercialização e distribuição.

A tendência é que este projeto evolua no sentido de desenvolverem-se estudos mais avançados de mercado, que deverão ser realizados para que o produto tenha um apelo mais comercial, bem como para que atenda as exigências de conforto e segurança de forma mais completa.

\section{Referências}

AMERICAN OCCUPATIONAL THERAPY ASSOCIATION - AOTA. Occupational therapy practice framework: domain and process. American Journal of Occupational Therapy, v. 56, n. 6, p. 609-639, 2002.

ANGELO, J.; BUNING, M. E. Adaptaç̃es de alta tecnologia para compensar a deficiência. In: TROMBLY, C. A.; RADOMSK, M. V. Terapia ocupacional para disfunções físicas. 5. ed. São Paulo: Livraria Santos, 2005. p. 389-420.

BAXTER, M. Projeto de produto: guia prático para o design de novos produtos. 2. ed. São Paulo: Edgard Blücher, 2003.

COOK, A. M.; HUSSEY, S. M. Assistive technologies. principles and practice. 2. ed. St. Louis: Mosby, 2002.

GAUZZl, L. D. V.; FONSECA, L. F. Classificação da Paralisia Cerebral. In: LIMA, C. L. A.; FONSECA L. F. Paralisia cerebral. Rio de Janeiro: Guanabara Koogan, 2004. p. 37-44.

GIANNI, M. A. C. Aspectos clínicos. In: MOURA, E. W.; SILVA, P. A. C. Fisioterapia: aspectos clínicos e práticos da reabilitação. São Paulo: Artes Médicas, 2005. p. 13-25.

MANCINI, M. C. et al. Comparação do desempenho de atividades funcionais em crianças com desenvolvimento normal e crianças com paralisia cerebral. Arquivos Neuropsiquiátricos, v. 60, n. 2-B, p. 446-452, 2002.

ORGANIZAÇÃO MUNDIAL DA SAÚDE. Organização Pan-Americana da Saúde - OPAS. Classificação internacional de funcionalidade. incapacidade e saúde. São Paulo: EdUSP, 2003.

PAIN, H.; McLELLAN, D. L. The relative importance of factors affecting the choice of bathing devices. British Journal of Occupational Therapy, v. 66, n. 9, p. 396-401, 2003.

SHEPHERD, J. Self-Care and adaptations for independent livisng In: CASE-SMITH, J. Occupational Therapy for Children. 4. ed. St. Louis: Mosby, 2001.

SOARES, M. M.; MARTINS, L. B. Design universal e ergonomia: uma parceria que garante acessibilidade para todos. In: ALMEIDA, A. T.; SOUZA, F. M. C. Produção e competitividade: aplicações e inovações. Recife: Ed. Universitária da UFPE, 2000. p. 127-156.

TABAQUIM, M. L. M.; LAMÔNICA, D. A. C. Análise perceptual de mães e filhos com paralisia cerebral sobre a atividade de banho. Arquivos Brasileiros de Paralisia Cerebral, v. 1, n. 1 , p. 30-34, 2004.

URBAN, G. L.; HAUSER, J. R. Design and marketing of new products. 2. ed. Englewood-Cliffs: Prentice Hall, 1993.

\title{
Development of a shower chair prototype for tetraplegic sufferers of cerebral palsy
}

\begin{abstract}
This study proposes to develop equipment which meets the demands of tetraplegics suffering from cerebral palsy and which promotes the adequate biomechanical posture of the caregiver during the shower activity of daily living. First, a bibliographic review was performed to define the terms referring to cerebral palsy, daily living activities (specifically showering), and assistive technology, in addition to listing the wheelchairs made principally by national assistive technology companies. Afterwards, data was collected from a questionnaire given to caretakers at medical-therapeutic treatment centers. At this point, anthropometric data and an analysis of the conditions under which baths were taken were also collected. The evaluation of the results obtained through the questionnaire, along with the practice and clinical experience of the researchers and engineers involved in this study, made it possible to develop and construct a real shower chair prototype.
\end{abstract}

Keywords

Cerebral palsy. Assistive technology. Daily living activity. Bath chair. Product development. 